\title{
Evidence Based Intrapartum Care and Factors among Obstetric Care Providers, Northwest Ethiopia: An Institution Based Cross-Sectional Study, 2015
}

\section{Kassahun $\mathrm{F}^{1 \#}$, Anteneh $\mathbf{M}^{2 *}$ and Wanzahun $\mathbf{G}^{3 *}$}

${ }^{1}$ Department of Midwifery, College of Medicine and Health Sciences, Arbaminch University, Arbaminch, Ethiopia

${ }^{2}$ Department of Nursing, College of Medicine and Health Sciences, University of Gondar, Gondar, Ethiopia

${ }^{3}$ Department of Public health, College of Medicine and Health Sciences, Arbaminch University, Arbaminch, Ethiopia

"Author contributed equally

\begin{abstract}
Introduction: Evidence-based intrapartum care uses the best available research on safety and effectiveness of specific practices to guide labor and delivery practice with the least harm intervention. Therefore this study was aimed to assess proportion of evidence-based intrapartum care and associated factors among obstetric care providers in Northwest Ethiopia, 2015.
\end{abstract}

Methods: An institution based cross-sectional study was conducted. The data was collected using self-administered questionnaire from April to May 2015. The study sites were five referral hospitals in Northwest Ethiopia. All obstetric care providers registered in each referral hospitals were participated.

Results: In adequate evidence is available towards intrapartum care, where the proportions of obstetric care providers practicing evidences during intrapartum phase were $38.3 \%$. While using health information seldom for teaching $(A O R=3.50,95 \% \mathrm{Cl}=1.30,9.40)$, providing in-service training for obstetric health care providers $(A O R=4.52$, $95 \% \mathrm{Cl}=1.61,12.71)$, adequate knowledge $(\mathrm{AOR}=5.30,95 \% \mathrm{Cl}=2.01,13.90)$ and favorable attitude $(\mathrm{AOR}=3.34,95 \%$ $\mathrm{Cl}=1.30,8.60)$.

Conclusion: Obstetric care providers in Northwest Ethiopia were giving intrapartum care not guided by best evidence available. Further investigation is needed to stipulate on current Intrapartum care among obstetric care providers in northwest Ethiopia.

Keywords: Evidence based labor care; Intrapartum, Labor and delivery; Hospitals; Obstetric care; Ethiopia

Abbreviations: AOR: Adjusted Odds Ratio; CI: Confidence Interval; EBP: Evidence based practice; OR: Odds Ratio; WHO:World Health Organization

\section{Introduction}

An estimated 300, 000 maternal deaths have occurred related to childbirth [1]. A large proportion of all maternal deaths take place in hospitals [2,3]. Most global maternal and newborn deaths are avoidable with quality health care provision, best be prevented investing mainly on an advanced obstetric care-including EmOC [3,4]. Women who received midwife led care were $21 \%$ less likely to have a fetal loss before 24 weeks' gestation, rather had more likely to have a spontaneous vaginal birth [5]. In Ethiopia, particular to Amhara regional state, the percentage of women giving birth at health facility remains $10.2 \%$ [6]. Delivery assisted by skilled provider is in fact the most important factor in reducing maternal mortality [7-9].

A cross-sectional study from Sweden reveals a $22.7 \%$ proportion of using evidence in intrapartum care, while $78 \%$ of women had received care concordant with evidence in Iranian social security hospital $[10,11]$. Another institution based study in California reported that $74.4 \%$ of women had received an evidence based intrapartum care [12].

A multi-institutional Californian study reveals age, profession, and qualification, and current position of care providers, including sex, age, qualification, employment status were associated with evidence based practice. An institution based cross-sectional study from Cameroon found out that age; sex, profession, and experience were associated with evidence based intrapartum care [13-16]. Several studies have shown that age, sex, profession, qualification, experience, access to internet, workshop, conferences, searching for the Cochrane database, were statistical associated with evidence based practice [17-19]. As an input for Intrapartum care, therefore, this study assesses the magnitude of and factors associated with evidence based practice in Amhara regional state referral hospitals.

\section{Materials and Methods}

\section{Study setting, design and period}

An institution based cross sectional study was conducted from April 2015 to May 2015. The study was conducted in Amhara regional state referral hospitals. The Amhara region locates with a location of $9^{\circ}-14^{\circ} \mathrm{N}$ and $36^{\circ}-40^{\circ} \mathrm{E}$ in Ethiopia's northwest. There are 5 referral hospitals, each hospital has assumed to be served for 5 million people, have 100-400 beds, 2000-3000 deliveries per year and 5-8 deliveries per day. According to the $2011 \mathrm{FMOH}$ report, skilled attendants $13.0 \%$ [2022]. There were about 254 registered obstetric care providers serving in the five referral hospitals (Figure 1).

${ }^{*}$ Corresponding author: Anteneh M, Department of Midwifery, College of Medicine and Health Sciences, Arbaminch University, Arbaminch, Ethiopia, Tel: 251920136228; E-mail: antenehmessele33@gmail.com

Wanzahun G, Department of Public health, College of Medicine and Health Sciences, Arbaminch University, Arbaminch, Ethiopia, E-mail: wanzanati2011@gmail.com

Received June 15, 2017; Accepted July 17, 2017; Published July 24, 2017

Citation: Kassahun F, Anteneh M, Wanzahun G (2017) Evidence Based Intrapartum Care and Factors among Obstetric Care Providers, Northwest Ethiopia: An Institution Based Cross-Sectional Study, 2015. Prim Health Care 7: 274. doi: $10.4172 / 2167-1079.1000274$

Copyright: (c) 2017 Kassahun F, et al. This is an open-access article distributed under the terms of the Creative Commons Attribution License, which permits unrestricted use, distribution, and reproduction in any medium, provided the original author and source are credited. 


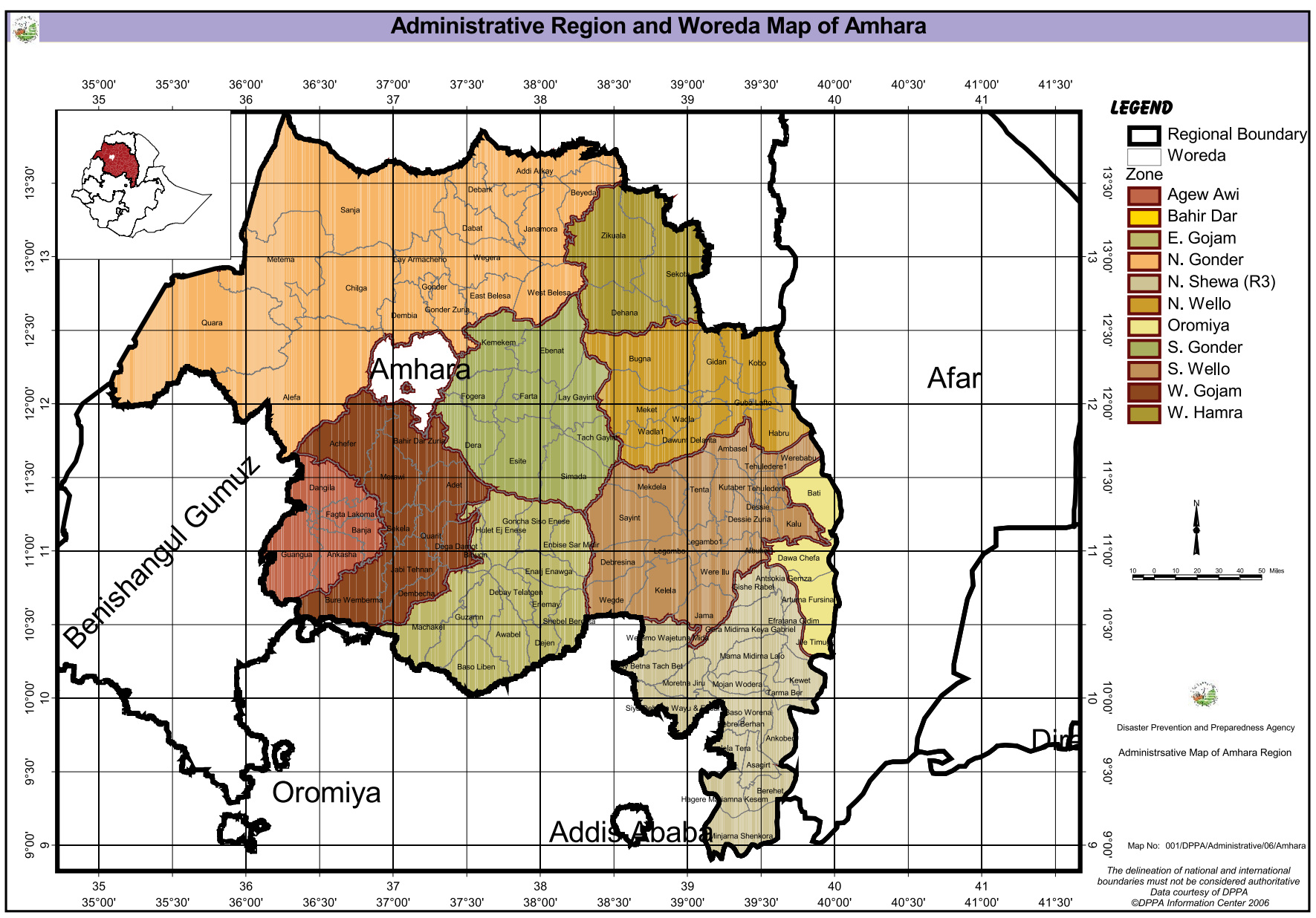

Figure 1: The location of the Amhara national regional state referral hospitals, Northwest Ethiopia, 2015.

\section{Study participants}

The source population was all obstetrics care providers in Amhara national regional state referral Hospitals. Study population was all obstetrics care providers who were available during the data collection period. All obstetrics care providers who were available during the data collection period and had provided obstetric care over the last 12 months in Amhara national regional state referral Hospitals were included.

\section{Variables of the study}

The dependent variable is evidence based intrapartum care. The independent variable includes Scio-economic factors (Age, sex, employment status, profession, qualification, position, marital status, experience), Organizational factors (access to computer and internet, managerial motivation, conference, and interactive EBP skill building workshops, cooperation, regular mentoring, patient condition, role clarity, source of health information) and Individual factors (use of computer, online searching, sources of health information, activities over the last 12 months, purpose of health information, knowledge and attitude).

\section{Operational definitions}

Evidence based intrapartum care: Obstetric care provides who scored greater than or equal to the median value of practice related questions of Intrapartum care.
Obstetric care providers: A certified health personnel who provide care for the woman during labor and delivery.

Adequate knowledge: Obstetric care provides who scored greater than or equal to the mean value of knowledge related questions of intrapartum care.

Favorable attitude: Obstetric care provides who scored greater than or equal to the mean value of attitude related questions of intrapartum care. It was measured by using a 5 -point Likert scale as individuals responding strongly agree for positive attitude was given scores of 5 and 1 for those who responded as strongly disagree, while the above scores was reversed for negative attitude questions.

\section{Sample size determination and sampling technique}

The minimum sample size required was computed using a single population proportion formula with the assumption of $50 \%$ proportion, at $95 \%$ certainty and maximum discrepancy of \pm 5 .

With these assumptions, the resulting sample size became 384 . Therefore, the final minimum sample size (n) became 403 considering $5 \%$ non-response rate. Due to sample size in adequacy all study population were taken as sample.

In Amhara regional state, there are 5 referral hospitals. All of them were selected, and based on the referral hospitals past 12 month staff registry, obstetric care providers who fulfill the inclusion criteria 
were identified and taken. The total sample size was proportionally allocated to each hospital. Then, questionnaire was distributed to each department where obstetric care providers are working. Data collection has been started considering the availed staff as starting point, everyone at exit.

\section{Data collection instrument}

After reviewing of the relevant literature, the questionnaire was adapted as appropriate to address the study objectives [23]. Primarily the questionnaire addressed socio-demographic, organizational, individual related information. The questionnaire was prepared in English translated in Amharic and back to English by a language expert. Finally, five data collectors, who were B.Sc. holders, well familiar with the study setting, and based on competency on local language, and resident of the study were selected to administer the data at the exit time from April to May, 2015. A two day training was given to the data collectors on how to approach study participants, how to use questionnaire, and data collection techniques.

\section{Data quality assurance}

A pre-test of the data collection tool was carried out on 20 obstetric care providers serving at Ayu General Hospitals in Debrebirhan city administration. Then, findings were discussed among data collectors so that the tool got adjusted. The whole process will be facilitated and checked thoroughly by the principal investigator. To ensure the completeness, accuracy and consistency of questionnaire meetings was held every day of the data collection. During these sessions thorough checking was done before the next day was started, which helped to crosscheck for their performance and improving proper data collection. Data double entry was done for reliability and correctness with the respective original data. In addition, computer data cleaning was undertaken. Three additional visits were done for absent respondents.

\section{Data processing and analysis}

The collected data were edited, coded and entered in Epi-Info version 7.1.2.0 computer package and then it was exported to SPSS (Statistical package for Social Sciences) version 20 for analysis. The entered data were cleaned and recoded further for construction and categorization of the variables, descriptive, and multivariate analysis. Binary logistic regression was used to identify factors associated with intrapartum care. Variables with a bivariable $P$ value less than 0.20 was fitted in to multivariable models for controlling the possible effect of confounders. Finally, the variables which had significant association with evidence based intrapartum care were identified on the basis of adjusted Odds Ratio (AOR), with 95\% confidence interval (CI) and $\mathrm{p}$-value $\leq 0.05$. The variables were entered to the multivariable logistic model using the Backward Stepwise (Likelihood Ratio) method.

\section{Ethical consideration}

Project approval was obtained from ethical review committee of University of Gondar College of medicine and health science, Department of Midwifery prior to the data collection has carried out. In addition, official letter of cooperation was given to each ARS (Amhara regional states) referral hospitals following discussion of the study objectives. An informed oral consent was also obtained concerning the aim of the study, risks and benefits, confidentiality issues, including withdrawal of any time they want to stop. Moreover, participants were assured that they had the right to withdraw from the study at any time they wish to leave. In fact, they were also being told as it had no place to affect their duty being given.

\section{Results}

\section{Socio-demographic factors}

A total of 212 obstetric care providers from the five referral hospitals in Amhara region were included with a $97.64 \%$ response rate. The median age of participants was 29 (IQR \pm 4 ). Out of the total 207 respondents, $116(56 \%)$ of them were male respondents. More than three fourth of respondents were working for full time in their respective hospital. The majority $106(51.20 \%)$ study participants were midwives by profession. More than $37 \%$ of study participants were Diploma holders (Table 1).

Further, 90 (43.50\%) of respondents were clinicians by duty. Among the entire respondents, $16(7.80 \%)$ had been working in labor and delivery ward for more than 10 years. Around quarter of participants were who have had obstetric associated working experience between 5 to 10 years. More than half of respondents had less than 5 years obstetric linked working experience.

\section{Organizational and individual related factors}

More than sixty percent of subjects had computer access at their work place. Among those who had access to computer near to three fourth values were using computer for reading. The amount 146 (70.50\%) represents those who had access to internet at their work place. About sixty four percent respondents were searching on internet for social Medias (Figure 2).

\begin{tabular}{|c|c|c|c|}
\hline S. No. & Variables & Frequency $(n=207)$ & Percent $(100 \%)$ \\
\hline 01 & $\begin{array}{l}\text { Age (years) } \\
\text { Less than } 25 \\
25 \text { to } 30 \\
\text { Above } 30\end{array}$ & $\begin{array}{c}18 \\
133 \\
56\end{array}$ & $\begin{array}{c}8.70 \\
64.30 \\
27.10\end{array}$ \\
\hline 02 & $\begin{array}{l}\text { Marital status } \\
\text { Single } \\
\text { Married }\end{array}$ & $\begin{array}{c}127 \\
80\end{array}$ & $\begin{array}{l}61.40 \\
38.60\end{array}$ \\
\hline 03 & $\begin{array}{l}\text { Employment status } \\
\text { Fulltime } \\
\text { Part-time }\end{array}$ & $\begin{array}{c}169 \\
38\end{array}$ & $\begin{array}{l}81.60 \\
18.40\end{array}$ \\
\hline 04 & $\begin{array}{l}\text { Profession } \\
\text { Medical doctor } \\
\text { Health officer } \\
\text { Midwife } \\
\text { Nurse }\end{array}$ & $\begin{array}{c}55 \\
38 \\
106 \\
8\end{array}$ & $\begin{array}{c}26.60 \\
18.40 \\
51.20 \\
3.90\end{array}$ \\
\hline 05 & $\begin{array}{l}\text { Qualification } \\
\text { Specialist } \\
\text { Master of science } \\
\text { General practitioners } \\
\text { Bachelor of science } \\
\text { Diploma }\end{array}$ & $\begin{array}{c}7 \\
6 \\
42 \\
74 \\
78\end{array}$ & $\begin{array}{c}3.38 \\
2.90 \\
20.29 \\
35.75 \\
37.68\end{array}$ \\
\hline
\end{tabular}

Table 1: Socio-demographic response of obstetric care providers in Amhara regional state referral hospitals, Northwest Ethiopia, 2015(n=207).

Mostly searched during online stay

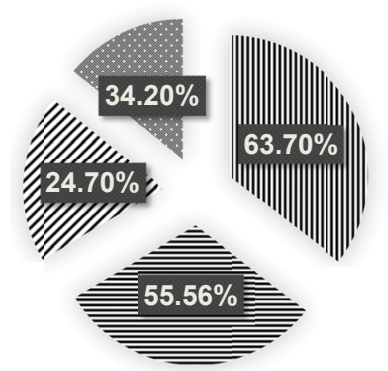

III Social networks

$=$ Online journals

"Cochrane database

WHO/RHL

Figure 2: Obstetric care providers mostly searched for during online stay in Amhara regional state referral hospitals, Northwest, Ethiopia, $2015(n=145)$. 
The vast majority $167(80.70 \%)$ were using text book either in addition or without an internet. Among the total 207 participants, $92(44.40 \%), 51(24.60 \%)$ and $38(18.4 \%)$ were confirming that they have been using health related journals, colleagues and conferences as source of health information respectively. Evidence based seminar participation leads the overall respondents with a $56.5 \%$ magnitude followed by those who took workshop (Figure 3).

$85(41.10 \%)$ said managerial role did motivated them to utilize evidences in to intra-partal practices. Patient condition was the leading motivator for participants with a $132(63.80 \%)$ response compared to 108 (52.2\%), 82 (39.60\%), 73 (35.30\%) and 65 (31.40\%) of whom motivated by evidence based related workshop, Staff cooperation, regular mentoring and role clarity correspondingly. The majority $167(80.70 \%)$ of participants were using health information to improve patient care. From the total subjects, 97 (46.9\%) and 62 (30\%) were using for teaching and research purposes.

\section{Magnitude of evidence based intrapartum care}

The overall magnitude of evidence based intrapartum care among obstetric care providers in ARS referral hospitals was $38.20 \%(95 \%$ $\mathrm{CI}=32.9 \%, 47 \%)$. Active third stage of labor management was done in about $93.20 \%$, while episiotomy accounts $60.4 \%$. The majority $77.3 \%$ of obstetric care providers were using partograph during first stage of labor (Figure 4).

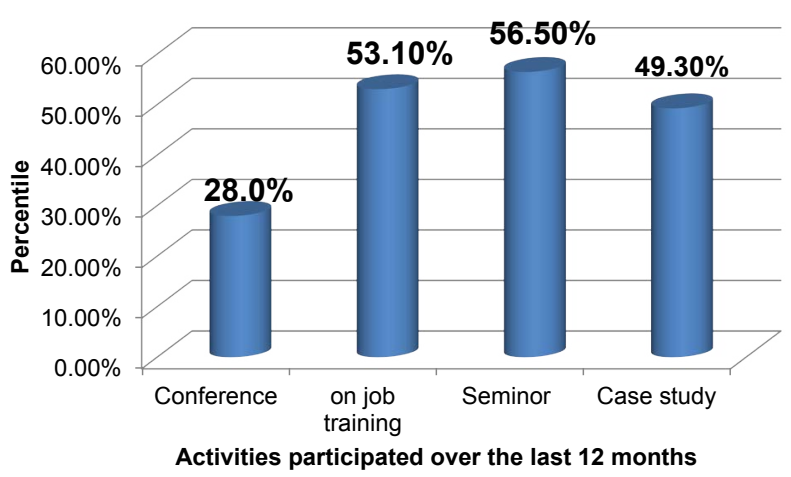

Figure 3: Obstetric care providers who had activities related to evidence based practice in Amhara national referral hospitals, Northwest, Ethiopia, 2015 $(n=207)$.

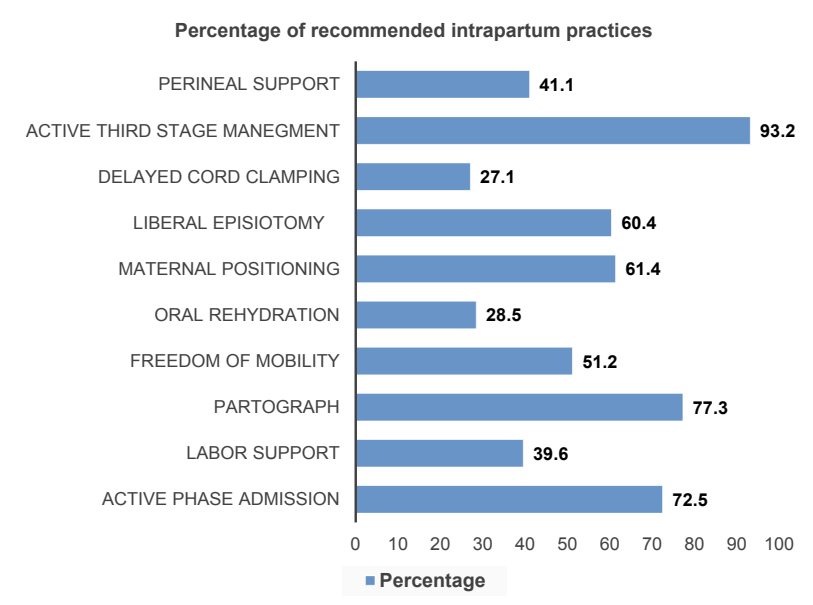

Figure 4: Percentage of recommended practices performed by obstetric care providers in Amhara regional state referral hospitals, north-west Ethiopia, 2015

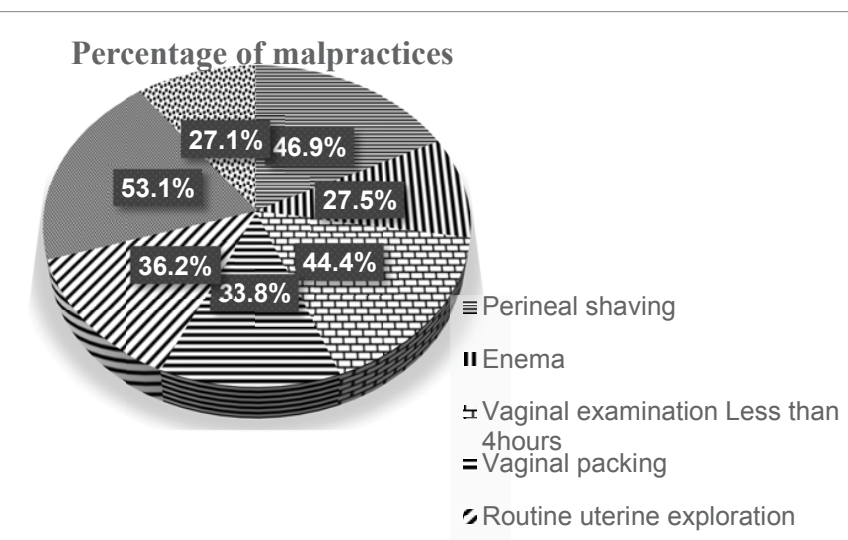

Figure 5: Percentage of malpractices done during intrapartum by obstetric care providers in Amhara regional state referral hospitals, Northwest Ethiopia, 2015.

Obstetric care providers were using fundal pressure in about $53.1 \%$ during second stage. About forty seven percent of obstetric care providers' were responded that they had done perinatal shaving during labor. Number of vaginal examination done by obstetric care providers in less than 4 hours duration was $44.4 \%$ (Figure 5).

\section{Factors associated with intrapartum evidence based practice}

Multivariable logistic regression showed that on job training on evidence based practice, not using health information for teaching purposes, knowledge, and attitude were significantly associated with evidence based intrapartum care.

Obstetric care providers who had taken training on evidence based practice were about 4.5 times more likely to perform an intrapartum care in agreement with best evidence available $(\mathrm{AOR}=4.5,95 \% \mathrm{CI}=1.61$, 12.71) than those who hadn't. Participants who failed to use health information for teaching purpose were about 4 times more likely to put evidence in to intrapartum care than who had used $(\mathrm{AOR}=3.50,95 \%$ $\mathrm{CI}=1.30,9.40)$.

In addition, having adequate knowledge about evidence based intrapartum care leads to more than 5 fold increase in utilization of intrapartum specific evidences in to practice $(\mathrm{AOR}=5.30,95 \% \mathrm{CI}=2.00$, 13.9). Statistical association also depicted that obstetric care providers having had favorable attitude towards evidence based intrapartum care were about 3 times more likely to perform intrapartum care with evidence than the other end $(\mathrm{AOR}=3.34,95 \% \mathrm{CI}=1.30,8.60)$ (Table 2$)$.

\section{Discussion}

The present study pointed out the overall proportion of obstetric care providers who were giving an intrapartum care in view of the best evidence available was $38.2 \%$. This was lower than a multi country study done in (Benin $70.1 \%$, Ecuador $77.6 \%$ and Rwanda 65\%); this might be due to difference in data collection tool and procedure, study participants, study setting [24]. In addition, time gap and better exposure to information sources also considered, as matter of fact, obstetric care providers with better access to information tend to have better motive to put in to practice and time discrepancy might have effect to change in practice.

On the other hand, the result of current study was higher than a study done in Sweden (22.7\%); this might be explained by a shift in strategies from routine obstetrics to major ones towards technology oriented interventions [25]. Perhaps, the government might be too 
Citation: Kassahun F, Anteneh M, Wanzahun G (2017) Evidence Based Intrapartum Care and Factors among Obstetric Care Providers, Northwest Ethiopia: An Institution Based Cross-Sectional Study, 2015. Prim Health Care 7: 274. doi: 10.4172/2167-1079.1000274

Page 5 of 7

\begin{tabular}{|c|c|c|c|c|}
\hline \multirow{2}{*}{ Variables } & \multicolumn{4}{|c|}{ Evidence based intrapartum care } \\
\hline & Yes (n) & No $(n)$ & COR $(95 \% \mathrm{Cl})$ & AOR $(95 \% \mathrm{Cl})$ \\
\hline \multicolumn{5}{|l|}{ Qualification } \\
\hline Higher & 12 & 33 & $0.45(0.20,0.98)$ & $1.80(0.44,7.40)$ \\
\hline Middle & 33 & 53 & $0.77(0.41,1.44)$ & $2.40(0.70,8.30)$ \\
\hline Lower ${ }^{\circledR}$ & 34 & 42 & 1 & 1 \\
\hline \multicolumn{5}{|c|}{ Computer for reading } \\
\hline Yes & 28 & 64 & $0.41(0.18,0.93)^{*}$ & $0.86(0.28,2.63)$ \\
\hline $\mathrm{No}^{\circledR}$ & 17 & 16 & 1 & 1 \\
\hline \multicolumn{5}{|c|}{$\begin{array}{l}\text { Scientific journals for health information } \\
\text { source }\end{array}$} \\
\hline \multicolumn{5}{|l|}{ Yes } \\
\hline \multirow[t]{2}{*}{$\mathrm{No}^{\circledR}$} & 29 & 63 & $0.60(0.34,1.06)$ & $0.57(0.19,1.72)$ \\
\hline & 50 & 65 & 1 & 1 \\
\hline \multicolumn{5}{|c|}{$\begin{array}{l}\text { Colleagues for health information } \\
\text { source }\end{array}$} \\
\hline \multicolumn{5}{|l|}{ Yes } \\
\hline \multirow[t]{2}{*}{$\mathrm{No}^{\circledR}$} & 14 & 37 & $0.53(0.27,1.06)$ & $1.06(0.32,3.53)$ \\
\hline & 65 & 91 & 1 & 1 \\
\hline \multicolumn{5}{|c|}{ Conference participation } \\
\hline Yes & 15 & 43 & $0.46(0.24,0.91)^{\star}$ & $0.34(0.12,0.99)^{*}$ \\
\hline $\mathrm{No}^{\circledR}$ & 64 & 85 & 1 & 1 \\
\hline \multicolumn{5}{|c|}{ Training on EBP } \\
\hline Yes & 50 & 60 & $1.95(1.10,3.50)^{\star}$ & $4.50(1.61,12.71)^{\star \star}$ \\
\hline $\mathrm{No}^{\circledR}$ & 68 & 29 & 1 & 1 \\
\hline \multicolumn{5}{|c|}{ Seminar participation } \\
\hline Yes & 37 & 80 & $0.53(0.30,0.93)^{*}$ & $0.59(0.19,1.79)$ \\
\hline $\mathrm{No}^{\circledR}$ & 42 & 48 & 1 & 1 \\
\hline \multicolumn{5}{|c|}{ Skill building workshop for motivation } \\
\hline \multicolumn{5}{|l|}{ Yes } \\
\hline \multirow[t]{2}{*}{$\mathrm{No}^{\circledast}$} & 38 & 72 & $0.65(0.40,1.14)$ & $0.40(0.14,1.02)$ \\
\hline & 43 & 56 & 1 & 1 \\
\hline \multicolumn{5}{|c|}{ Role clarity for motivation: } \\
\hline Yes & 20 & 45 & $0.63(0.34,1.17)$ & $0.41(0.20,1.10)$ \\
\hline $\mathrm{No}^{\otimes}$ & 59 & 83 & 1 & 1 \\
\hline \multicolumn{5}{|c|}{ Health information for teaching } \\
\hline Yes & 29 & 68 & 1 & 1 \\
\hline $\mathrm{No}^{\otimes}$ & 50 & 60 & $1.60(1.10,3.50)^{*}$ & $3.50(1.30,9.40)^{*}$ \\
\hline \multicolumn{5}{|l|}{ Knowledge } \\
\hline Inadequate ${ }^{\circledR}$ & 29 & 85 & 1 & 1 \\
\hline Adequate & 50 & 43 & $3.41(1.90,6.13)^{\star \star \star}$ & $5.30(2.00,13.9)^{\star * *}$ \\
\hline \multicolumn{5}{|l|}{ Attitude } \\
\hline Non-favorable ${ }^{\circledR}$ & 30 & 93 & 1 & 1 \\
\hline Favorable & 49 & 35 & $4.34(2.40,7.90)^{\star \star \star}$ & $3.34(1.30,8.60)^{\star * \star}$ \\
\hline
\end{tabular}

NB: Higher: Specialist's, Resident's, Master of Science's; Middle: General practitioners, Bachelor of Science's; Lower: Diploma's; ${ }^{* \star *}=\mathrm{P}<0.001,{ }^{* *}=\mathrm{P}<0.01,{ }^{*}=\mathrm{P}<0.05$, ${ }^{\circledR}=$ references

Table 2: Bivariable and multivariable analysis of distribution of factors associated with evidence based intrapartum practice in Amhara regional state referral hospitals, Northwest Ethiopia, 2015.

focused in striving to reduce maternal mortality since it's the final year of millennium development yet to be achieved. Time gap, study population, data collection tool and procedure might have a role. In fact, referral teaching hospitals in Amhara regional stated have been hosting postgraduate students.

The current study is lower than study done in California (74.4\%), Iran (78\%), Brazil (50\%) [13,26,27]. This may be possibly due to cross cultural difference, divided loyalty, self-selection, and limited number of staffs serving in the hospital [28]. Moreover, providers characteristics, additional duties other than labor, having every relatives aside each laboring mother would disturb the ward and privacy breach might be a concern. In fact, maternal rehydration is subjected to individual evaluation. It also implies that study setting, data collection tool and study participants might have role. In addition, a high case flow in referral hospitals might obscure obstetric care providers not to give due attention. Indeed, most of laboring mothers come after labor has advanced and complicated. Variation might also be due to health facility mentoring and motivation in overseas.

\section{Factors associated with evidence based intrapartum care}

On job training on evidence based practice in this study was found 
to be strongly associated with evidence based intrapartum care, where obstetric care providers were near to 5 times more likely to adhere to evidence based Intrapartum care than those who had no training at their institution $(\mathrm{AOR}=4.50,95 \% \mathrm{CI}=1.61,12.71)$. This finding does not agree with studies in Italy, Sweden, and Cameroon. The discrepancy might be due to variation in study setting, study participants, data collection tool and procedure $[15,17,29]$. On the other hand, variation in terms of time might have contributed since as time advances change in practice is likely. In fact, obstetric care providers having had on job training might have better motive for practice because of the insight they had from the training. In addition, since referral hospitals are training sites for BEmONC (Basic emergency obstetric and newborn care) trainees, obstetric care providers might have initiation to put new evidence in to practice.

Not using health information for teaching purposes was found to be associated with evidence based intrapartum care, while obstetric care providers who did not used health information for teaching were about 4 times more likely to perform intrapartum care concordant to best evidences than those who had used teaching purposes $(\mathrm{AOR}=3.50$, $95 \% \mathrm{CI}=1.30,9.40$ ). This does not agreed with a study done in Sweden [29]. This could be, clinicians with academic base were responsible to teach students underneath them. In fact, educators spend more time teaching students than they do teaching them how to use research in practice [30]. Obstetric care providers who had used health info for teaching might lack awareness how to put research findings in to clinical practice, not motivated, unsupportive working environment [30]. Clinicians were more attached with patients who increase their likely to use evidence in to practice, probably due to a motive to enhance patient care. This was reflected in this study, while relatively more clinicians were using evidence into practice than those who had academic roles.

In the present study, having a favorable attitude towards evidence based intrapartum care had a triple fold increase in evidence based intrapartum care $(\mathrm{AOR}=3.3495 \% \mathrm{CI}=1.31,8.60)$. A result from Spain also showed a significant association between favorable attitude and evidence based practice, a study from Croatia supplemented that attitude of clinicians were significantly associated with evidence based practice, Italia $[15,19,21]$. In addition, another study from US added that practitioners having good attitude towards were significantly associate with evidence based practice [20]. The current study finding is not in agreement with the Italian study, presumably due to variation in data collection tool, procedure, study subjects, and study area. In fact, a good attitude resulted from adequate knowledge might affect evidence based intrapartum practicum. Scientific meeting and conferences might held often since most of referral hospitals are hosting postgraduate student and they are close to information other than being busy with routine practice. It is plausible that obstetric care providers exposure to such environment could change their attitude so as to foster to put evidences in to practice specially to intrapartum related ones.

Obstetric cares providers who had adequate knowledge were ahead of 5 times more likely to utilize evidences in their routine obstetric care during Intrapartum care $(\mathrm{AOR}=5.3,95 \% \mathrm{CI}=2.01,13.90)$, Italian [15]. The current study's result is in line with a cross-sectional study done in Cameroon [17]. A multi-institutional study done in US showed that health practitioners who had adequate knowledge were statistically associated with evidence based practice. The reason might be due to the fact that, those who had adequate knowledge would have an increased enthusiasm to put into practice. It could also be due to various factors which contribute for increased performance. For instance, a trend which brings about change a theory in to practice like presence of role model and well-experienced practitioner, patient condition, evidence based training, workshops and journal clubs. In addition, it also implies that acquiring adequate knowledge is a key for evidence based intrapartum care.

\section{Conclusion}

The current practice of intrapartum care among obstetric care providers in Amhara Regional State referral hospitals was low. Training on evidence based practice, not using health information for teaching purpose, provider's knowledge, and attitude were factors significantly associated with evidence based intrapartum care.

The result of this study showed that it is a very suitable time to give supervisory attention current performance on intrapartum care on regular basis. Devotion to participate in changing clinical practice plays a role on obstetric care provider's performance. Providing a short term on job training on principles of evidence based practice might enhance the intrapartum care. Besides, investigate reason for using ineffective practices and barriers for beneficial intrapartum cares gives insight for future researcher to be addressed qualitatively.

\section{Acknowledgement}

We would like to express our appreciation to University of Gondar for funding staffs of Midwifery department and each respondent for providing us valuable information.

\section{References}

1. Carine Ronsmans WJG (2006) Maternal mortality: Who, when, where and why? Lancet 368:1189-200

2. Althabe F, Gibbons L, Ciapponi A, Alema'n A (2008) Strategies for improving the quality of health care in maternal and child health in low- and middle-income countries: An overview of systematic reviews. Paediatr Perinat Epidemiol 22: 42-60.

3. Spector JM, Lashoher A, Agrawal P, Lemer C, Dziekan G, et al. (2013) Designing the WHO Safe childbirth checklist program to improve quality of care at childbirth. Int J Gynaecol Obstet 122: 164-168.

4. Global, Regional and National Levels of Maternal Mortality, 1990-2015 (2015) A systematic analysis for the global burden of disease study. Lancet 388:1775 812.

5. Sandall J, Devane D, Soltani H, Hatem M, Gates S (2010) Improving quality and safety in maternity care: the contribution of midwife-led care. J Midwifery Womens Health 55: 255-261.

6. Oza S, Cousens SN, Lawn JE (2015) Estimation of daily risk of neonatal death including the day of birth, in 186 countries in 2013: A vital-registration and modelling-based study. Lancet Glob Health 2: e635-44.

7. Asrade Abate (2015) Joint Review mission final report: federal democratic republic of ethiopia,ministry of health. Federal Democratic Republic of Ethiopia Ministry of Health.

8. Ethiopia demographic and health survey Addis Ababa, Ethiopia and Calverton, Maryland, USA 2011.

9. Agency CS (2015) Ethiopia mini demographic and health survey, Addis Ababa, Ethiopia, p: 108.

10. Sandin-Bojo AK, Kvist LJ (2008) Care in labor: A swedish survey using the bologna score. Birth 35: 321-328.

11. Aghlmand S, Akbari F, Lameei A, Mohammad K, Small R, et al. (2008) Developing evidence-based maternity care in Iran: a quality improvement study. BMC Pregnancy Childbirth.

12. Shaw-Battista J, Fineberg A, Boehler B, Skubic B, Woolley D, et al. (2011) Obstetrician and nurse-midwife collaboration: Successful public health and private practice partnership. Obstet Gynecol 118: 663-672.

13. lyengar K, Jain M, Thomas S, Dashora K, Liu W, et al. (2015) Adherence to evidence based care practices for childbirth before and after a quality improvement intervention in health facilities of Rajasthan, India. BMC Pregnancy Childbirth 14: 270 . 
Citation: Kassahun F, Anteneh M, Wanzahun G (2017) Evidence Based Intrapartum Care and Factors among Obstetric Care Providers, Northwest Ethiopia: An Institution Based Cross-Sectional Study, 2015. Prim Health Care 7: 274. doi: 10.4172/2167-1079.1000274

14. Brown CE, Ecoff L, Kim SC, Wickline MA, Rose B, et al. (2010) Multi-institutional study of barriers to research utilisation and evidence-based practice among hospital nurses. J Clin Nurs 19:1944-1951.

15. De Vito C, Nobile CG, Furnari G, Pavia M, De Giusti M, et al. (2009) Physicians' knowledge, attitudes and professional use of RCTs and meta-analyses: A cross-sectional survey. Eur J Public Health 19: 297-302.

16. Bostrom AM, Rudman A, Ehrenberg A, Gustavsson JP, Wallin L. (2013) Factors associated with evidence-based practice among registered nurses in Sweden: A national cross-sectional study. BMC Health Serv Res 13: 165.

17. Tita AT, Selwyn BJ, Waller DK, Kapadia AS, Dongmo S (2006) Factors associated with the awareness and practice of evidence-based obstetric care in an African setting. BJOG 113: 1060-1066.

18. Fawole A, Oladapo O, Enahoro F, Akande E (2008) Acceptance of evidencebased reproductive health care among postgraduate specialist trainees in Nigeria. Int J Gynaecol Obstet 102: 3-7.

19. Novak K, Miric D, Jurin A, Vukojevic K, Aljinovic J, et al. (2010) Awareness and use of evidence-based medicine databases and cochrane library among physicians in Croatia. Croat Med J 51:157-164.

20. Breimaier HE, Halfens RJ, Lohrmann C (2011) Nurses' wishes, knowledge, attitudes and perceived barriers on implementing research findings into practice among graduate nurses in Austria. J Clin Nurs 1744-1756.

21. Moreno-Casbas T, Fuentelsaz-Gallego C, de Miguel AG, Gonzalez-Maria E Clarke SP (2011) Spanish nurses' attitudes towards research and perceived barriers and facilitators of research utilisation: A comparative survey of nurses with and without experience as principal investigators. J Clin Nurs 20: 1936-47.
22. Directorate FMoHPP (2012) Health and health related indicators. 2012: 74.

23. Group TS-OS (2008) Use of evidence-based practices in pregnancy and childbirth: South-east Asia optimising reproductive and child health in developing countries project. PLoS ONE 3: 7.

24. Burkhalter B WE, S Harvey, M Boucar, S Djibrina, J Hermida, et al. (2006) Quality of obstetric care observed in 14 hospitals in Benin, Ecuador, Jamaica and Rwanda. Oper Res Res pp: 1-6.

25. Ann-Kristin Sandin-Bojo R, Linda J (2008) Care in Labor: A swedish survey using the bologna score. Birth 35: 321-328.

26. Do Carmo Leal M, Pereira AP, Domingues RM, Theme Filha MM, Dias MA, et al. (2015) Obstetric interventions during labor and childbirth in Brazilian low-risk women. Cadernos de saude publica 1: S1-16.

27. Hodnett ED GS, Hofmeyr GJ, Sakala C, Weston J (2011) Continuous support for women during childbirth. Cochrane Database Syst Rev.

28. Wallis $L$ (2012) Barriers to implementing evidence-based practice remain high for U.S. nurses: Getting past "we've always done it this way" is crucial. Am J Nurs 112: 15.

29. Rebecca RD, Sco M, Sonia S (2014) Barriers and facilitators to evidence-based nursing in Colombia: Perspectives of nurse educators, nurse researchers and graduate students. Invest Educ Enferm 32: 9-21.

30. Caroline E, Brown LE, Son CK, Mary AW, Barbara R, et al. (2010) Multiinstitutional study of barriers to research utilisation and evidence-based practice among hospital nurses. J Clin Nurs 19: 1944-1951. 